Relations industrielles

Industrial Relations

\title{
L'évolution du professionnalisme au Québec, Québec, Office des professions du Québec, 1976, 145 p.
}

\section{Gilles Dussault}

Volume 31, numéro 3, 1976

URI : https://id.erudit.org/iderudit/028733ar

DOI : https://doi.org/10.7202/028733ar

Aller au sommaire du numéro

Éditeur(s)

Département des relations industrielles de l'Université Laval

ISSN

0034-379X (imprimé)

1703-8138 (numérique)

Découvrir la revue

Citer ce compte rendu

Dussault, G. (1976). Compte rendu de [L'évolution du professionnalisme au Québec, Québec, Office des professions du Québec, 1976, 145 p.] Relations industrielles / Industrial Relations, 31(3), 495-496.

https://doi.org/10.7202/028733ar

Tous droits réservés (C) Département des relations industrielles de l'Université Laval, 1976
Ce document est protégé par la loi sur le droit d'auteur. L’utilisation des services d'Érudit (y compris la reproduction) est assujettie à sa politique d'utilisation que vous pouvez consulter en ligne.

https://apropos.erudit.org/fr/usagers/politique-dutilisation/ 
De plus, les commentaires ajoutent à la substance même du volume en fixant plus clairement les limites partielles d'un champ d'études et de recherches, sans prétendre vraiment, pour l'instant, à la définition d'un objet proprement scientifique. Ici et là, pourtant, apparaissent divers éléments utiles à cette difficile définition: ainsi, l'action sociale des salariés et la transformation du salariat, dans la mesure où celle-là agit efficacement sur celle-ci [à l'exclusion des mesures de sécurité sociale mises de l'avant par l'Etat et au niveau desquelles, toutefois, a œuvré indirectement l'action syndicale].

Le commentateur prémunit le lecteur contre l'hypertrophie du juridique, péché mignon non seulement en France mais en Europe généralement, dans l'explication des phénomènes de relations industrielles; d'où l'accent sur l'entreprise comme système social complexe à base d'accommodements et de conflits multiples, de luttes pour le pouvoir, d'équilibre entre le formel et l'informel, et ainsi de suite. Le processus même de l'industrialisation, qui apporte une modification des rapports de droit et de force entre les divers agents de production, est étudié comme objet propre [?] des relations industrielles, au moins potentiellement. Ces rapports obéissent-ils avant tout aux impératifs technoéconomiques, ou si plutôt tout doit être ordonné au politique comme seul véritable principe d'ordonnance des relations industrielles? Le commentateur, par ses propos et par les textes qu'il juxtapose, permet une certaine synthèse de ces points de vue opposés.

L'intercontinentalité des textes et commentaires proposés apporte une nette distinction entre l'Europe et l'Amérique du Nord quant au lieu, au niveau, au centre efficace de pouvoir et d'interaction dans l'entreprise et dans la société, ainsi qu'au rôle de l'État dans l'équilibre des forces en présence dans le dur jeu des relations industrielles. Le régime américain met en évidence des rapports très institutionnalisés entre des entreprises géantes et de puissants syndicats, au niveau même de l'établissement, avec leur cortège de décentralisation, d'arbitrage, d'absentéisme relatif de l'État [sinon par conciliation et médiation occasionnelles]; les conventions collectives, fort détaillées, sont la loi de l'usine. En Europe, on trouve plutôt des clauses fort larges couvrant l'ensemble des travailleurs, donc minimales, pouvant donc être dépassées au niveau de l'entreprise. La négociation se joue à un niveau élevé: la branche régionale et souvent nationale, parfois même l'action interprofessionnelle. En Europe, les conventions semblent être complèmentaires du droit étatique paternel plutöt que consécutives à un traité bilatéral employeurs-syndicats.

Les deux textes [de Dunlop et de Fürstenberg] traduits par le commentateur sont couchés dans un français élégant. Comme traducteur, M. Sellier s'est constamment refusé à la solution facile de l'expression anglaise entre guillemets, comme auteur, il a paressé quelque peu en "job evaluation» [pp. $192+193$ ] avec ses «shop-stewards" [pp. $201+203$ ]. Nos collègues français qui s'aventurent dans la littérature anglaise des relations de travail, surtout l'américaine, n'auront désormais plus d'excuse; ils ont depuis quelques mois à leur disposition le très utile Dictionnaire canadien des relations $d u$ du travail du professeur Gérard DION [Québec: Les Presses de l'Université Laval, 1976, $662 \mathrm{pp}$.], lequel contient un volumineux «Vocabulaire français-anglais, anglais-français des relations professionnelles».

Roger CHARTIER

Accapulco

L'évolution du professionnalisme au Québec, Québec, Office des professions du Québec, $1976,145 \mathrm{p}$.

Après trois années d'activité intense, depuis la mise en route de la réforme des professions, l'Office des professions du Québec croit le moment venu de préciser ses orientations quant au développement du professionnalisme au Québec. Surtout qu'un des effets immédiats de l'adoption du Code des professions a été l'affluence de demandes d'incorporation (23 au total, entre avril 1974 et juillet 1976) venant de toutes sortes de groupes et associations, depuis les acupuncteurs jusqu'aux traducteurs, en passant par les mesureurs de bois et les décorateurs-ensembliers, aspirant à l'autogestion professionnelle.

Cette popularité du professionnalisme et certaines difficultés d'application de la loi 250 , ont amené le service de recherche de l'Office des professions à s'interroger 
sur la notion même de profession ainsi que sur les activités des corporations professionnelles, déjà reconnues par la loi, en matière de protection du public: car l'on sait que le changement majeur introduit par la loi 250 dans l'organisation professionnelle est l'affirmation du principe qu'une corporation professionnelle n'a de raison d'être autre que la protection du public et non l'intérêt de ses membres. Une brève synthèse de la littérature sociologique sur les professions et une enquête auprès de 29 professions reconnues (sont exclues les 9 professions reconnues en 1973 seulement) conduisent l'Office aux conclusions suivantes: 1) il n'y a pas de définition de la notion de profession qui permette de discriminer, avec des critères objectifs, les activités professionnelles des autres activités de travail ; 2) le niveau d'activité d'une corporation en matière de protection du public, sans égard à la qualité de cette activité, est, de façon significative, plus élevé chez les professions qui détiennent l'exclusivité du titre et de l'exercice professionnels et qui possèdent les caractéristiques suivantes: "être composées de membres exerçant majoritairement en pratique privée, œuvrer dans un secteur d'activité où la clientèle est surtout composée d'individus, bénéficier de ressources financières importantes et disposer d'un nombre de membres relativement élevé» (p. 63).

Ces conclusions inspirent à l'Office une politique restrictive en matière de constitution de nouvelles corporations professionnelles. En effet, dorénavant on exigera des groupements désireux d'obtenir le statut professionnel qu'ils possèdent certaines caractéristiques: forte proportion de membres en pratique privée, clientèle composée surtout d'individus et exercice dans un champ de connaissances dont l'étendue rend très difficile le contrôle efficace de la qualité de la pratique professionnelle par d'autres types de réglementation. L'Office prévoit donc que l'octroi du privilège d'exercice exclusif sera plutôt rare; toutefois, il entend faire un usage plus libéral de l'octroi du privilège d'un titre réservé, qui informerait le public que le professionnel qui le détient offre des garanties de compétence reconnues.

Pour ce qui est de la situation particulière des corporations à titre réservé déjà existantes, et qui ont été nombreuses à réclamer le contrôle de l'exercice, l'Office ne croit pas qu'il y ait lieu de modifier leur statut. A celles qui déplorent leur faible pouvoir, l'Office entend proposer de se regrouper avec d'autres corporations du même champ d'activité: on suggérera, par exemple, le regroupement des psychologues et des conseillers d'orientation.

La politique de l'Office des professions, du moins celle qu'il propose au législateur, est de ne pas favoriser le développement du corporatisme professionnel au Québec et de n'octroyer le statut de profession reconnue que dans les cas où il est évident qu'on a épuisé toutes les autres formes de contrôle de l'exercice d'une activité en vue de protéger le public. Ce choix est logique et il était souhaitable; cependant il laisse en plan la question de la situation actuelle du professionnalisme au Québec. Plusieurs, parmi les corporations existantes, ne répondent en rien aux critères d'octroi du statut professionnel; c'est à force de lobbying et de pressions politiques de toutes sortes qu'elles ont obtenu d'être incorporées et non parce qu'elles ont satisfait des critères objectifs. Si on fait l'exercice de leur appliquer les critères de la loi 250 ainsi que ceux que l'Office propose dans ce document, on ne voit pas comment des corporations comme celles des administrateurs-agréés, des conseillers en relations industrielles, des agronomes, des urbanistes, des travailleurs sociaux - pour ne nommer que celles-là - pourraient obtenir aujourd'hui le statut professionnel. Certaines sont même incapables de définir avec un minimum de précision leur champ d'activité ou l'acte professionnel dont elles prétendent assurer la qualité. L'Office des professions ne pourra éviter d'aborder cette question délicate encore longtemps s'il veut maintenir la crédibilité acquise depuis sa fondation.

Université Laval

Gilles DUSSAULT

Code du travail du Québec. Édition révisée, par Me Philip Cutler, c.r., L.L.D., Montréal, Les Livres Toundra, 1976 $650 \mathrm{p}$.

A la suite des recherches effectuées pour l'obtention de son doctorat en droit à l'université de Montréal en 1968, Philip Cutler publiait deux ans plus tard un ouvrage qui a connu un grand succès dans le monde des relations du travail.

L'auteur, suivant une méthode simple et pratique, y analysait chacun des articles du Code du travail du Québec et fournissait la jurisprudence canadienne et québécoise ainsi que la doctrine. Cet ouvrage de référence destiné aux praticiens des relations du travail était épuisé depuis plusieurs années. Une réédition s'imposait d'autant 